\title{
An internet shopping user adoption model using an integrated TTF and UTAUT: Evidence from Iranian consumers
}

\author{
Nahid Bozorgkhou*
}

M.Sc. degree in MBA Communications and Information Technology Research Institute, Iran

\begin{tabular}{l}
\hline C H R O N I C L E \\
\hline Article history: \\
Received September 28, 2014 \\
Accepted 28 December 2014 \\
Available online \\
December 282014 \\
\hline Keywords: \\
Internet shopping \\
Task technology fit (TTF) \\
Unified theory of acceptance and \\
usage of technology (UTAUT) \\
Iran
\end{tabular}

\section{Introduction}

The recent advances on information technology (IT) has led to the replacement of face to face conventional services by new virtual services, and the World Wide Web has substantially changed customer expectations in connection with speed, accuracy, pricing and service quality (Vrechopoulos et al., 2001). With the proliferation of virtual space, geographical distance has lost its meaning, and availability as well as easy access to services is one of the components of services offered by organizations (Shim et al., 2001). Internet shopping is one of the services provided by the organizations in the virtual environment in order to speed up service delivery and increase convenience for customers. In fact, due to existing technology, going to stores for shopping has become a non-essential process, and electronic access to purchasing resources has provided faster shopping and in most cases cheaper and easier (Novak et al., 2000). Internet shopping is a buying method in which the customer receives information about goods and makes a purchase using IT and by referring to sales bases. In this way, unlike the usual manner, the consumer has not seen and touched the commodity before delivery and has made a purchase only on the basis of graphical schema and information contained in Web sites (Blake et al., 2003).

*Corresponding author.

E-mail addresses: Bozorgkhou@csri.ac.ir (N. Bozorgkhou)

(c) 2015 Growing Science Ltd. All rights reserved. doi: $10.5267 / j . m s l .2014 .12 .017$ 
Despite many benefits that internet shopping have for customers, for some reasons such as unfamiliarity with the technology (Limayem et al., 2000), distrust to cyberspace (Donthu \& Garcia, 1999) and enjoyment of shopping (Bei et al., 2004), internet shopping customers have not received much attention, and internet offering and sales capacity are much greater than internet purchase and demand (Shim et al., 2001). To this end, many studies have been performed in order to expand internet shopping practice among buyers and their overall objective is to increase internet transactions, and internet purchase and sale (Vrechopoulos et al., 2001). This study also investigates factors influencing the rise of internet shopping among Iranian consumers.

\section{Literature review}

Many studies have been carried out on internet shopping using different models and approaches. Yoo and Park (2005) emphasized on the importance of perceived purchase trust and risk. According to researchers, the most important factor for increasing internet shopping is to improve customer distrust in cyberspace or the desired website. Other researchers have also emphasized the importance of this issue. Factors such as distrust to receipt of goods ordered with the desired properties (Park \& Kim, 2003), distrust to timely delivery of goods (Dickson, 2000), distrust to prices (Page \& LepkowskaWhite, 2002) are the most important components affecting consumer trust to internet shopping process. About the perceived risk, Yoo and Park (2005) state many internet users questioned that one can really purchase over the Internet or not. According to this group of users, the risk of some problems is high because of lack of funds transfer, lack of order registration, or difficulties in delivery.

Accordingly, these people prefer face to face purchases in stores. Other researchers have focused on various aspects of perceived risk. Mejia et al. (2009) emphasized on the sensitivity of users about information security and integrity of selling bases for keeping their information. Novak et al. (200) emphasized the risk perceived by consumer on the quality of goods sold on the virtual environment. Other researchers often emphasized a combination of factors and reasons influencing the spread of internet shopping practice. Kim et al. (2010) emphasized the importance of perceived information and perceived enjoyment of a virtual shopping more than anything else. They also considered factors such as trust to the website and customer obsession as the motivators of buying and assessed its role in the shopping process as significant and positive. Mejia et al. (2009) also found the relationship between income levels and shopping and emphasized the direct relationship between the two. Poddar et al. (2009) proposed a model in which three variables (site, site quality and customer preferences) were identified as contributing factors in internet shopping. Kim and Gupta (2009) proposed the most important factor for internet shopping as "perceived value", which consists of two components: "perceived price" and "perceived risk".

Laohapensang (2009) proposes the most important factors affecting tendency to use internet shopping as follows:

- Consumer's attitude: What is the buyer's perception of internet shopping and its benefits?

- Perceived behavioural controls: To what extent would the buyer use conservative and risk- free patterns?

- Social norms: To what extent is internet shopping recognized as an acceptable activity and value in the community?

Connolly and Bannister (2008) propose the most important factors affecting consumer trust and the rise of internet shopping as follows:

- Perceived safety: Trust to the website, especially the timely delivery of products ordered,

- Perceived privacy: To what extent will be personal information maintained?

- Perceived integrity: To what extent would consistency exist between buyer expectations 
and the results obtained?

- Perceived competence and benefits: What are the time and economic advantages of shopping via the website?

\section{Research model and hypotheses}

The research model is derived from the model used by Zhou et al. (2010). The model variables include task-technology fit, expectation performance, expectation effort, facilitating conditions and social impacts, as shown in Fig. 1. The research hypotheses were formed based on this model.

$\mathrm{H}_{1}$ : There is a significant relationship between task features and task-technology fit.

$\mathrm{H}_{2}$ : There is a significant relationship between technology features and task-technology fit.

$\mathrm{H}_{3}$ : There is a significant relationship between task-technology fit and internet shopping.

$\mathrm{H}_{4}$ : There is a significant relationship between internet shopping and performance expectation.

$\mathrm{H}_{5}$ : There is a significant relationship between internet shopping and effort expectation.

H6: There is a significant relationship between internet shopping and social impacts.

$\mathrm{H}_{7}$ : There is a significant relationship between internet shopping and facilitating conditions.

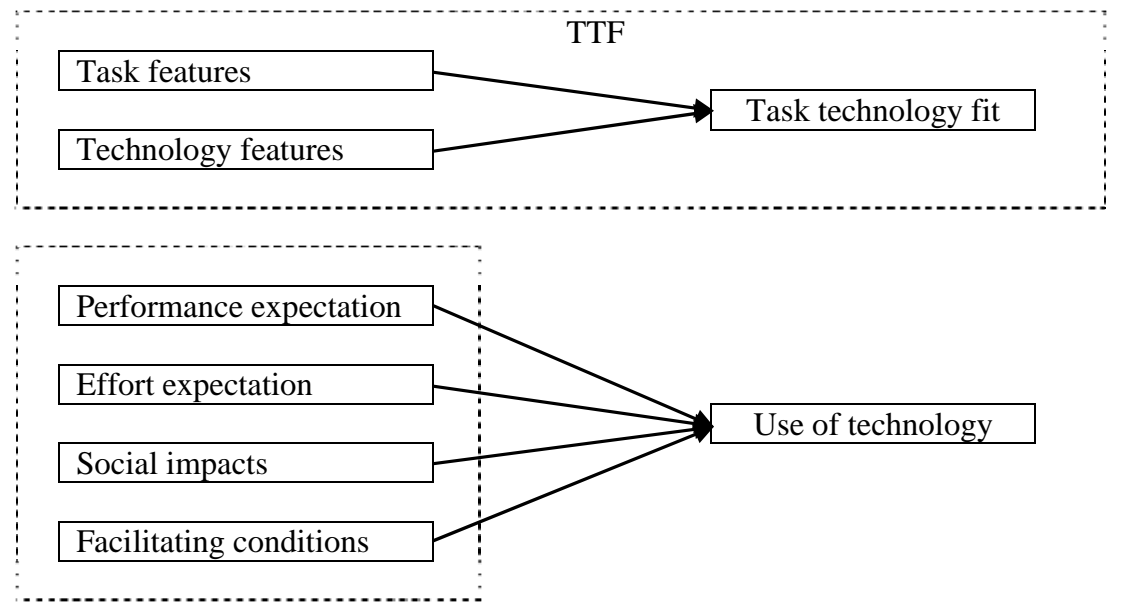

Fig. 1. The research model (Zhou et al., 2010)

The population includes people who live in Tehran city with at least one experience of internet shopping. Since the population is unlimited, the Cochran formula for sample size determination is used to determine the sample size. At the $5 \%$ error level, the sample size was obtained as 384 . In order to obtain more accurate results, a total of 400 questionnaires were distributed among which 392 usable questionnaires were collected. According to the standard questionnaire (Zhou et al., 2010) and approval of 5 academics and experts in the field of IT, the reliability of the questionnaire was assured. Cronbach's alpha coefficient was used to assess the test reliability. Cronbach's alpha was obtained for task features (0.758), technology features (0.744), task-technology fit (0.769), performance expectation (0.791), effort expectation (0.720), social impacts (0.736) and facilitating conditions (0.755). According to Cronbach's alpha values for variables (all above 0.7), the reliability of the study is approved. Fig. 2 demonstrates personal characteristics of the participants. 


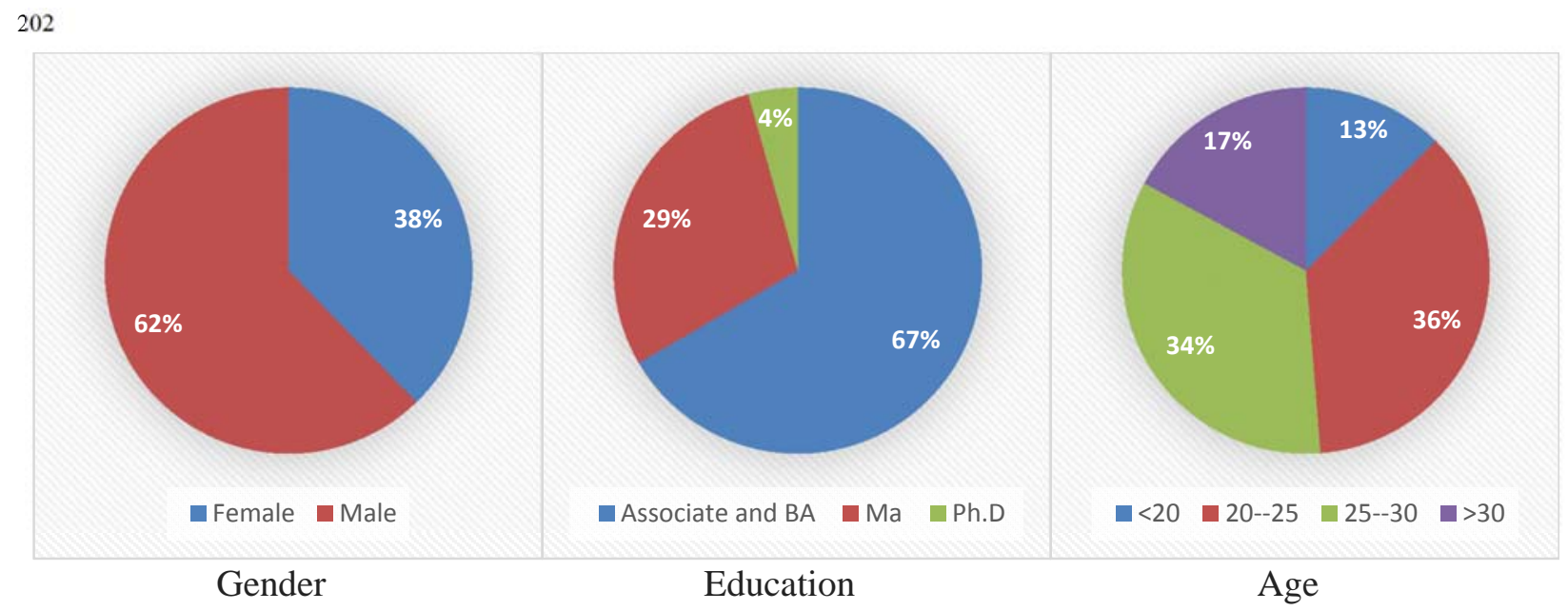

Fig. 2. Personal characteristics of the participants

\section{Results and discussion}

Table 1 shows the correlation among different components of the survey. According to the results of Table 1, there is a significant positive relationship between task features and task-technology fit (Sig: $0.000, r=0.455)$. There is a significant positive relationship between technology features and tasktechnology fit (Sig: 0.0000, $r=0.587$ ), (Sig: 0.000, $r=0.230$ ). There is a significant relationship between performance expectation and internet shopping (Sig: 0.000, r=636). No significant relationship was reported between effort expectation and internet shopping (Sig: 0.658). There is a significant direct relationship between internet shopping and social impacts (Sig: 0.000, $\mathrm{r}=0.246$ ). Finally, there is a direct positive relationship between internet shopping and facilitating conditions (Sig: $0.000, \mathrm{r}=0.367)$.

\section{Table 1}

The correlation matrix

\begin{tabular}{|c|c|c|c|c|c|c|c|c|}
\hline & Facilitating & Social & Effort expectation & Performance & Technology & Task features & Fit & Internet \\
\hline Internet shopping & $.367 * *$ & $.246 * *$ & 0.1 & $.636^{* *}$ & $.227 * *$ & $.308^{* *}$ & $.230 * *$ & 1 \\
\hline Sig. & 0.000 & 0.000 & 0.658 & 0.000 & 0.000 & 0.000 & 0.000 & . \\
\hline Task-technology & $.123^{*}$ & $.251^{* *}$ & 0.004 & $.175^{* *}$ & $.587^{* *}$ & $.455^{* *}$ & 1 & \\
\hline Sig. & 0.015 & 0.000 & 0.944 & 0.001 & 0.000 & 0.000 & & \\
\hline Task features & 0.023 & $.121 *$ & 0.001 & $.235 * *$ & $.397^{* *}$ & 1 & & \\
\hline Sig. & 0.652 & 0.016 & 0.952 & 0.000 & 0.000 & 0.000 & & \\
\hline Technology features & $.113^{*}$ & $.222 * *$ & 0.026 & $.197 * *$ & 1 & & & \\
\hline Sig. & 0.026 & 0.000 & 0.607 & 0.000 & 0.000 & & & \\
\hline $\begin{array}{l}\text { Performance } \\
\text { expectation }\end{array}$ & $.272 * *$ & $.115^{* *}$ & $.147 * *$ & 1 & & & & \\
\hline Sig. & 0.000 & 0.023 & 0.003 & & & & & \\
\hline Effort expectation & $.292 * *$ & $.193^{* *}$ & 1 & & & & & \\
\hline Sig. & 0.000 & 0.000 & 0.000 & & & & & \\
\hline Social impacts & $.329 * *$ & 1 & & & & & & \\
\hline Sig. & 0.000 & 0.000 & & & & & & \\
\hline
\end{tabular}

The significant relationship between task features and technology features shows that the services and benefits of internet shopping are consistent with the users' needs and thus, the promotional practices can be used to develop this method. If the task-technology fit relationship were weak, we would hardly be able to increase the number of internet shoppers. In addition, even with extensive advertisement, customers would not welcome it. Zhou et al. (2010) also stressed the importance of the fit between task and technology features and considered it as one of the factors influencing the development of any new technology. 


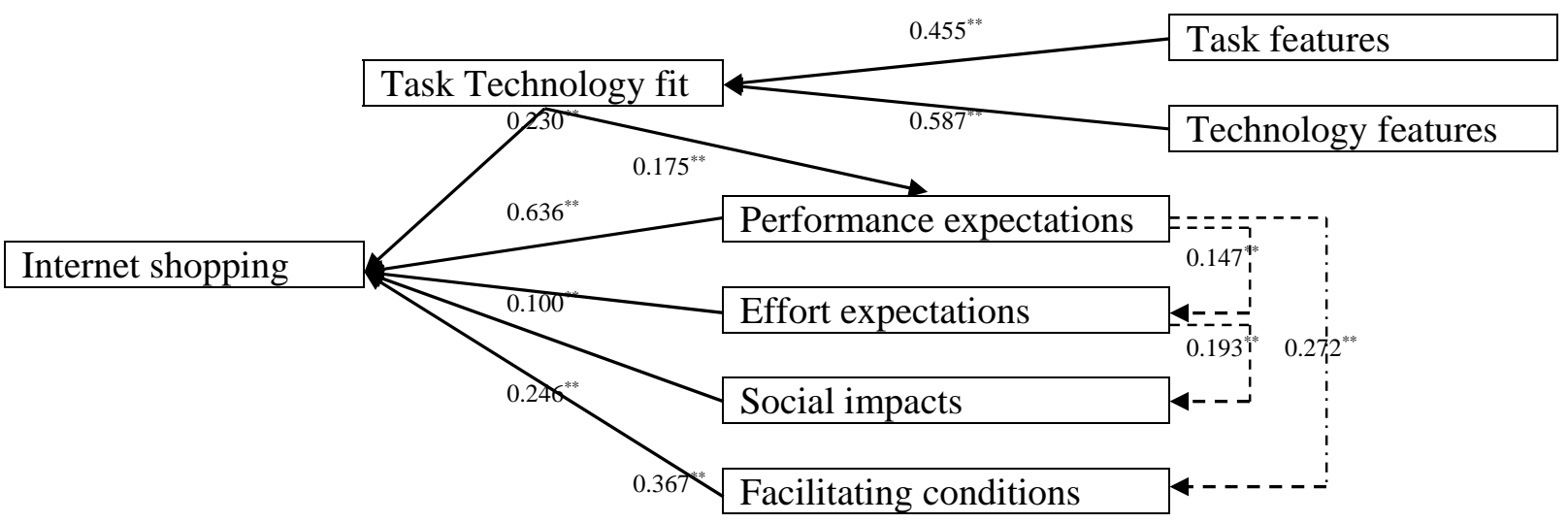

Fig. 3. The results $\left({ }^{* *}\right.$ Sig. $\left.<0.05\right)$

\subsection{Performance expectation -internet shopping}

According to users, the use of Internet for making purchases helps reduce costs and is one of the most important factors affecting internet shopping. Increased speed and efficiency of purchasing process has been also emphasized. Accordingly, performance expectation has led to more users for internet shopping. Previous research (Shim et al., 2001; Dickson, 2000) also noted that new technologies were constantly being evaluated by users. If users find that the use of new technology can lead to increased well-being or reduced costs, they will take a positive approach towards it. Due to internet shopping, users do not need to refer to stores and wait in lines for purchase. This has led to increased user comfort. In addition, any work done at home can lead to higher comfort. In addition, time-saving has also led to increased user satisfaction of internet shopping services. In fact, internet shopping services has managed to meet the performance expectations of staff better than traditional methods (Park \& Kim, 2003). Thus, introducing the performance and benefits of internet shopping can be seen as the best factor for extension of its use. Moreover, enhanced capabilities, especially in terms of security and reliability can encourage more users to take advantage of these services.

\subsection{Effort expectation -internet shopping}

The lack of a significant relationship between effort expectation and increased internet shopping suggests that regardless of the difficulty in using this technology, users prefer to use it due to its benefits. The results also indicate that only a small percentage of users have been deterred from using it because of its difficulty. But there is another reason: Most users are young and familiar with the Internet. They also can easily learn new functionality and make use of it. Thus, effort expectation is less important for many users.

\subsection{Social impacts - internet shopping}

In most previous researches, there were not much emphasis on social impacts. But in this study, which was conducted on Iranian users, this is more important due to wider social relations and the impact of family environments and friendship groups. Evidence suggests that social impacts have been effective in two stages. The first stage is before using internet shopping services. Many users have been encouraged to use these services by friends and family members. In other words, social impacts are a stimulus that encourages people to use these services. The second stage is after use in which social impacts can be considered as a bonus. That is, as users expect higher performance due to internet shopping services, they expect to receive positive feedback from the social environment.

\subsection{Facilitating conditions - internet shopping}

Facilitating conditions are important in that the use of new technologies often require new information and tools. Users normally resist against anything new, and facilitating conditions actually act to remove 
this resistance (Donthu \& Garcia, 1999). The results show that with more facilitating conditions, more users tend to use internet shopping services. This is important because it can serve as a tool for internet sales companies. In other words, internet shopping service companies and executives may not have the ability to change other variables (social conditions, performance expectation and effort expectation), but facilitating conditions enable them to increase education and informative advertising and also dedicate professionals in order to answer questions or solve potential problems of users, increasing buyers' tendency to their internet shopping site.

\section{References}

Bei, L. T., Chen, E. Y., \& Widdows, R. (2004). Consumers' online information search behavior and the phenomenon of search vs. experience products. Journal of Family and Economic Issues, 25(4), 449467.

Blake, B. F., Neuendorf, K. A., \& Valdiserri, C. M. (2003). Innovativeness and variety of internet shopping. Internet Research, 13(3), 156-169.

Connolly, R., \& Bannister, F. (2008). Factors influencing Irish consumers' trust in internet shopping. Management Research News, 31(5), 339-358.

Dickson, P. R. (2000). Understanding the trade winds: The global evolution of production, consumption, and the Internet. Journal of Consumer Research, 27(1), 115-122.

Donthu, N., \& Garcia, A. (1999). The internet shopper. Journal of Advertising Research, 39(3), 52-58.

Kim, G., Shin, B., \& Lee, H. G. (2009). Understanding dynamics between initial trust and usage intentions of mobile banking. Information Systems Journal, 19(3), 283-311.

Kim, H. W., \& Gupta, S. (2009). A comparison of purchase decision calculus between potential and repeat customers of an online store. Decision Support Systems, 47(4), 477-487.

Limayem, M., Khalifa, M., \& Frini, A. (2000). What makes consumers buy from Internet? A longitudinal study of online shopping. Systems, Man and Cybernetics, Part A: Systems and Humans, IEEE Transactions on, 30(4), 421-432.

Laohapensang, O. (2009). Factors influencing internet shopping behaviour: a survey of consumers in Thailand. Journal of Fashion Marketing and Management, 13(4), 501-513.

Mejia, M., Peña, N., Muñoz, J. L., \& Esparza, O. (2009). A review of trust modeling in ad hoc networks. Internet Research, 19(1), 88-104.

Novak, T. P., Hoffman, D. L., \& Yung, Y. F. (2000). Measuring the customer experience in online environments: A structural modeling approach. Marketing science, 19(1), 22-42.

Page, C., \& Lepkowska-White, E. (2002). Web equity: a framework for building consumer value in online companies. Journal of Consumer Marketing, 19(3), 231-248.

Park, C. H., \& Kim, Y. G. (2003). Identifying key factors affecting consumer purchase behavior in an online shopping context. International Journal of Retail \& Distribution Management, 31(1), 16-29.

Poddar, A., Donthu, N., \& Wei, Y. (2009). Web site customer orientations, Web site quality, and purchase intentions: The role of Web site personality. Journal of Business Research, 62(4), 441450.

Shim, S., Eastlick, M., Lotz, S., \& Warrington, P. (2001). An internet repurchase intentions model: the role of intention to search. Journal of Retailing, 77(3), 397-416.

Vrechopoulos, A. P., Siomkos, G. J., \& Doukidis, G. I. (2001). Internet shopping adoption by Greek consumers. European Journal of Innovation Management, 4(3), 142-153.

Yoo, S.J., \& Park, N.H. (2005). The Effect between cognitive characteristics, relationship quality and purchase intention on shopping mall web site. Journal of Small Business Studies, 27(1), 195-218.

Zhou, T., Lu, Y., \& Wang, B. (2010). Integrating TTF and UTAUT to explain mobile banking user adoption. Computers in Human Behavior, 26(4), 760-767. 